\title{
A rare cause of ST segment elevation: avoiding critical errors in an emergency
}

\author{
Avneet Garg ${ }^{D}$, Rakendra Singh, Mansimranjit Kaur, Vinita Jindal
}

Adesh Institute of Medical Sciences and Research, Bathinda, Punjab, India

A 72-year-old female with a history of hypertension and chronic cough presented with worsening dyspnoea, left-sided chest pain, and vomiting that had been present for two days. In the emergency department, her vital signs were stable but room air oxygen saturation was 85\%. An electrocardiogram (ECG) showed ST segment elevation in precordial leads (Figure 1A). A chest X-ray showed a left-sided opacity with an air-fluid level and a mediastinal shift to the opposite side (Figure 1B). Laboratory studies showed arterial blood gas (ABG) measurements of 7.47/27.5/52/19.9 on 4 litres/minute oxygen via nasal cannula, white blood cell count of $11.3 \mathrm{~K} / \mu \mathrm{L}$, a haemoglobin level of $15.3 \mathrm{~g} / \mathrm{dL}$, and a serum sodium level of $128 \mathrm{mmol} / \mathrm{L}$. The serum troponin level was $<0.01 \mathrm{ng} / \mathrm{mL}$.

1. What is your provisional diagnosis?

2. What is the probable cause of ST segment elevation?

Physical examination showed bowel sounds along the left lower chest with absent air entry. Contrast-enhanced computed tomography of the chest showed a large diaphragmatic hernia causing a mediastinal shift to the other side (Figure 1C, D). Misdiagnosis of diaphragmatic hernia as hydropneumothorax is not uncommon in both acute and chronic settings and can commonly lead to incorrect chest tube placement [1]. Various findings that may suggest a diagnosis of diaphragmatic hernia rather than hydropneumothorax include hearing bowel sounds on chest auscultation, curling up of the nasogastric tube in the stomach, history of preceding/ associated traumatic injuries, an elevated hemidiaphragm, irregular diaphragmatic contour, a gas bubble or air-fluid levels in the chest above the expected level of the diaphragm, compression atelectasis of the lower lobe, and intrathoracic intra-abdominal viscera with or without a focal constriction (collar sign) [2, 3]. An increase in intra-abdominal pressure can lead to protrusion of the abdominal content into the thoracic cavity. This is what we believe happened in our case as the history of chronic cough and vomiting may have caused increased intra-abdominal pressure in our patient.
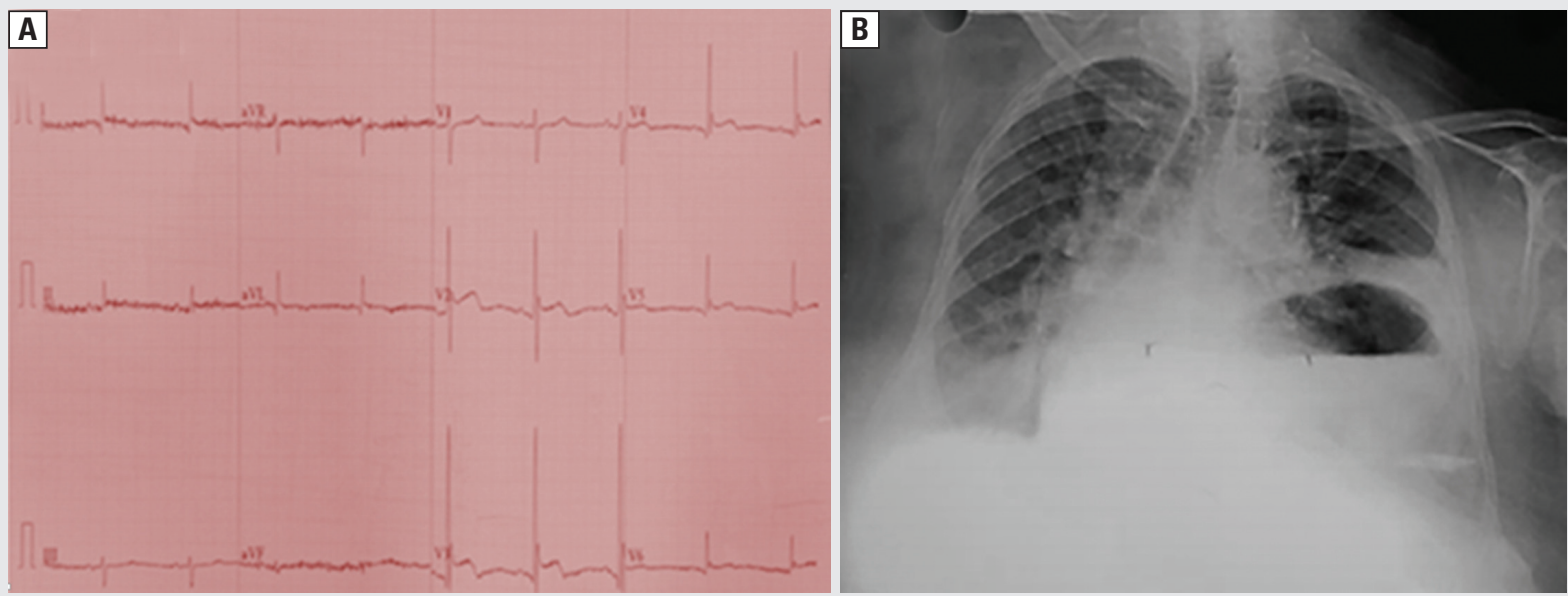

Figure 1A. Electrocardiography showing sinus bradycardia and ST elevation in leads V3, V4, and V5; B. Chest X-ray posteroanterior view showing an air-fluid level in the left hemithorax

Address for correspondence: Avneet Garg, Adesh Institute of Medical Sciences and Research, Bathinda, Punjab, India, e-mail: dravneetgarg@gmail.com Conflict of interest: None declared.

DOI: 10.5603/ARM.a2021.0108 | Received: 03.06.2021 | Copyright (C 2021 PTChP | ISSN 2451-4934 | e-ISSN 2543-6031

This article is available in open access under Creative Common Attribution-Non-Commercial-No Derivatives 4.0 International (CC BY-NC-ND 4.0) license, allowing to download articles and share them with others as long as they credit the authors and the publisher, but without permission to change them in any way or use them commercially. 

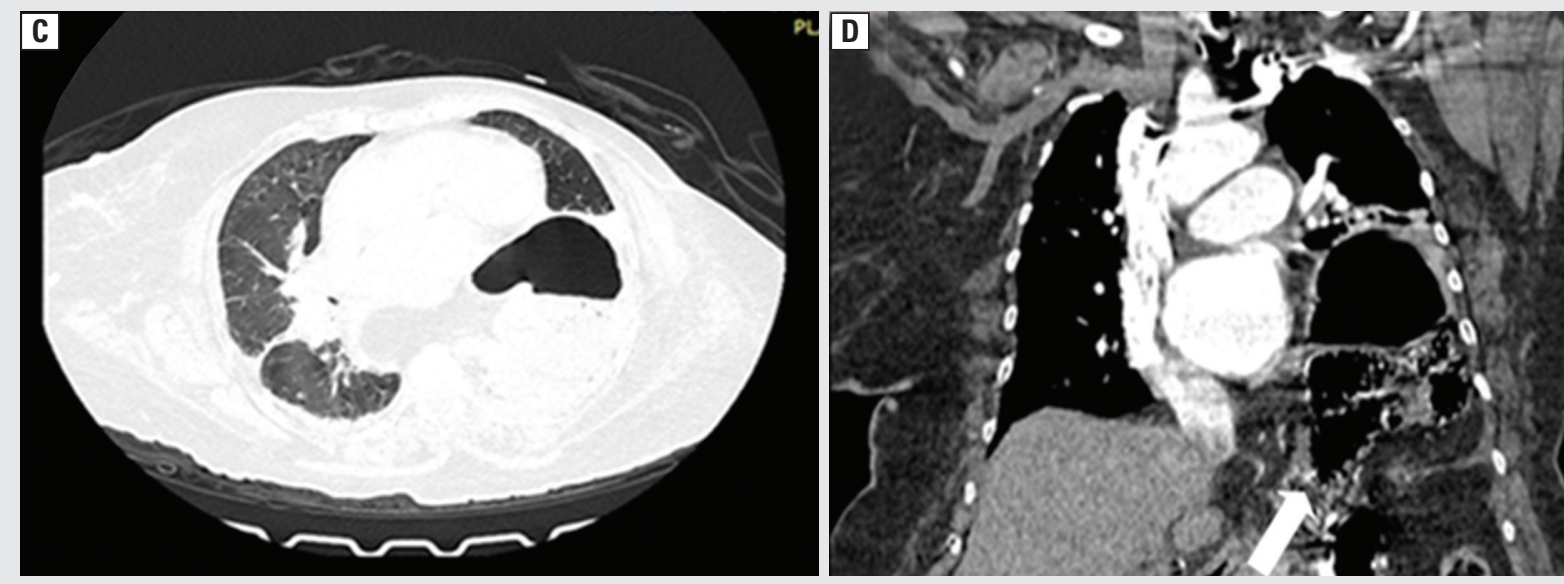

Figure 1C. Computed tomography (CT) pulmonary window axial section showing an air-fluid level in the left hemithorax; D. CT mediastinal window coronal section white arrow showing a defect in the left hemidiaphragm with herniation of the stomach and bowel loops into the left hemithorax, and a mediastinal shift towards the right side

ST segment elevation on the electrocardiogram in our case was attributed to a large diaphragmatic hernia causing a mediastinal shift. Serial troponin levels and a subsequent coronary angiogram were normal. Tension pneumothorax and hiatal hernias causing ST segment elevation have been reported in literature [4]. Possible mechanisms include cardiac rotation, pressure on the heart and coronary vessels leading to decreased coronary flow and ischemia, acute right ventricular strain, or dilation from hypoxia and decrease in preload due to increased intra-abdominal pressure [5]. One or more of the said mechanisms may be responsible for ST changes observed in our case.

Our experience in this case is particularly useful for emergency medicine physicians and cardiologists who must remember that diaphragmatic hernias can closely mimic hydropneumothorax and can cause ST segment changes on electrocardiograms. This case also emphasizes the utmost importance of physical examination in emergency medicine in order to avoid critical errors.

\section{References:}

1. Shiyovich A, Vladimir Z, Nesher L. Left spontaneous pneumothorax presenting with ST-segment elevations: a case report and review of the literature. Heart Lung. 2011; 40(1): 88-91, doi: 10.1016/i.hrtlng.2010.09.007, indexed in Pubmed: 21320674.

2. Feldman T, January CT. ECG changes in pneumothorax. A unique finding and proposed mechanism. Chest. 1984; 86(1): 143-145, doi: $10.1378 /$ chest.86.1.143, indexed in Pubmed: 6734277.

3. Targhetta R, Bourgeois JM, Chavagneux R, et al. Ultrasonographic approach to diagnosing hydropneumothorax. Chest. 1992; 101(4): 931-934, doi: 10.1378/chest.101.4.931, indexed in Pubmed: 1555465.

4. Harte S, Casey RG, Mannion D, et al. When is a pneumothorax not a pneumothorax? J Pediatr Surg. 2005; 40(3): 586-587, doi: 10.1016/i.jpedsurg.2004.11.019, indexed in Pubmed: 15793743 .

5. Shapiro MJ, Heiberg E, Durham RM, et al. The unreliability of CT scans and initial chest radiographs in evaluating blunt trauma induced diaphragmatic rupture. Clin Radiol. 1996; 51(1): 27-30, doi: 10.1016/s0009-9260(96)80214-5, indexed in Pubmed: 8549043. 